\title{
Students' Changing Attitudes and Aspirations Towards Physics During Secondary School
}

\author{
Richard Sheldrake $^{1}$ (D) Tamjid Mujtaba $^{1}$ • \\ Michael J. Reiss ${ }^{1}$
}

Published online: 16 November 2017

(C) The Author(s) 2017. This article is an open access publication

\begin{abstract}
Many countries desire more students to study science subjects, although relatively few students decide to study non-compulsory physics at upper-secondary school and at university. To gain insight into students' intentions to study non-compulsory physics, a longitudinal sample (covering 2258 students across 88 secondary schools in England) was surveyed in year 8 (age 12/13) and again in year 10 (age 14/15). Predictive modelling highlighted that perceived advice, perceived utility of physics, interest in physics, selfconcept beliefs (students' subjective beliefs of their current abilities and performance) and home support specifically orientated to physics were key predictors of students' intentions. Latent-transition analysis via Markov models revealed clusters of students, given these factors at years 8 and 10. Students' intentions varied across the clusters, and at year 10 even varied when accounting for the students' underlying attitudes and beliefs, highlighting that considering clusters offered additional explanatory power and insight. Regardless of whether threecluster, four-cluster, or five-cluster models were considered, the majority of students remained in the same cluster over time; for those who transitioned clusters, more students changed clusters reflecting an increase in attitudes than changed clusters reflecting a decrease. Students in the cluster with the most positive attitudes were most likely to remain within that cluster, while students in clusters with less positive attitudes were more likely to change clusters. Overall, the cluster profiles highlighted that students' attitudes and beliefs may be more closely related than previously assumed, but that changes in their attitudes and beliefs were indeed possible.
\end{abstract}

Keywords Cluster $\cdot$ Latent-transition analysis $\cdot$ Physics $\cdot$ Science $\cdot$ Stem

Electronic supplementary material The online version of this article (https://doi.org/10.1007/s11165-0179676-5) contains supplementary material, which is available to authorized users.

Richard Sheldrake rsheldrake@ioe.ac.uk 


\section{Introduction}

It has been the desire of many countries to increase the number of students studying science subjects in order to meet an expected demand for increased numbers of scientists and to address under-representation and promote equity (ACOLA 2013; EACEA 2011; Royal Society 2014). However, in England, while secondary school students have often considered science to be fairly interesting and relevant for wider careers, relatively few have chosen to study (non-compulsory) upper-secondary science subjects, especially physics, and few have aspired to become scientists (DeWitt et al. 2014; Institute of Physics 2014; Jenkins and Nelson 2005; Royal Society 2008).

Research has highlighted that students' studying aspirations or intentions have often followed from their attitudes and motivational beliefs, including their interest in science, their perceived utility of science (thinking that science leads to various benefits such as fostering skills and facilitating careers) and their confidence in their own science abilities (Regan and DeWitt 2015; Tripney et al. 2010). Given these factors, research has also focused on identifying naturally emergent clusters of students who hold distinct profiles of views towards science, although little such research has occurred in England (Andersen and Chen 2016; Chow et al. 2012).

The research presented here aimed to address this gap, in order to provide greater insight into who does, and who does not, intend to study upper-secondary physics in England and how changes may occur over time. The study was contextualised to England, but also offered important insights to international audiences: the study confirmed key factors associated with students' intentions to study upper-secondary physics; given these factors, the study then identified distinct clusters of students with particular profiles of views and identified any changes in cluster membership over time.

\section{Background}

In England, students study various subjects at General Certificate of Secondary Education (GCSE) or equivalent level during years 10 and 11 (ages 14/15 to 15/16), where science is compulsory. Students can then undertake upper-secondary education at Advanced Level General Certificate of Education (A-Level) or equivalent level during years 12 and 13 (ages $16 / 17$ to $17 / 18$ ), where no subjects are compulsory.

Relatively few students in England have chosen to study non-compulsory uppersecondary physics, compared to biology and chemistry, and compared to subjects in other areas. Additionally, girls, students from families with lower incomes, and students from some minority backgrounds have also been less likely to study non-compulsory physics (Homer et al. 2014; Institute of Physics 2014; Royal Society 2008). It remains difficult to isolate any single cause, however. Any effects following from students' gender or their other background characteristics, or other influences following from schools, have often been found to be relatively small when compared to other factors (Bennett et al. 2013; Gill and Bell 2013; Homer et al. 2014). Instead, students' intentions to study science subjects have most strongly associated with their own attitudes towards science, such as their interest in science and their perceived utility of science, together with their confidence in their own abilities (Jensen and Henriksen 2015; Mellors-Bourne et al. 2011; Regan and DeWitt 2015; Tripney et al. 2010; Vidal Rodeiro 2007). 
Essentially, differences in students' attitudes and beliefs regarding science have helped to explain differences in students' intentions and choices (DeWitt and Archer 2015). For example, compared to girls, boys have expressed that science was easier, more interesting, more preferable than other subjects, and more relevant for careers (Bennett and Hogarth 2009; Jenkins and Nelson 2005). Nevertheless, students' attitudes may be influenced by, or follow from, various aspects of life, linking with their contexts and backgrounds. For example, in England, parents from some minority backgrounds (including East-Asian/Chinese and SouthAsian/Indian backgrounds) have considered science to be a valuable indicator of success and a pre-requisite for following preferred careers and have often conveyed these attitudes to their children (Archer and Francis 2006; Archer et al. 2014; Wong 2012). However, limited knowledge of particular careers and few existing role models in physics (but role models being present within other areas) may mean that such students have considered scientific fields such as medicine to be more relatable and achievable than physics (Wong 2016).

\section{Students' Attitudes and Beliefs Within Conceptual Frameworks}

Research within science education has increasingly considered specific attitudes and beliefs, while concurrently applying motivational theories as interpretative and explanatory frameworks (Bøe and Henriksen 2015). Recent research has, for example, often applied the expectancy-value model of motivated behavioural choices, within social-cognitive theory, in order to gain insight into students' intentions and choices (Bøe 2012; Bøe and Henriksen 2013; Wang and Degol 2013).

The expectancy-value model proposes that studying and career choices are closely related to someone's 'expectations for success' and the 'subjective values' attached to the various options considered to be available; these beliefs are themselves influenced by someone's wider context and environment, such as someone's family and background, together with earlier experiences (Eccles 2009; Eccles et al. 1983). These assumptions have been broadly supported by studies that have, for example, found that contextual aspects of students' lives, such as their parents' beliefs and their classroom experiences, have associated with the students' expectations and subjective values about science, which have then associated with their aspirations or choices (DeWitt et al. 2011; Thomas and Strunk 2017; Wang 2012).

'Expectations for success' have been measured as students' confidence in their current abilities (their self-concept beliefs) and/or their confidence in their future capabilities (their self-efficacy beliefs), following social-cognitive theory where higher confidence can be motivational and where lower confidence can be limiting (Bandura 1977; Bong and Clark 1999; Bong and Skaalvik 2003). These two conceptualisations of confidence have been proposed to closely associate (Eccles 2009; Wigfield and Eccles 2000) and have indeed associated with students' choices (DeWitt and Archer 2015; Eccles and Wang 2016; Guo et al. 2016). Students' confidence essentially reflects their subjective interpretations of their abilities and attainment (Bong and Clark 1999; Bong and Skaalvik 2003) and has associated with students' intentions and choices similarly to objective measures of attainment (Wang 2012; Wang et al. 2013).

Subjective values have been measured as interest value (intrinsic interest and enjoyment in doing something), utility value (extrinsic usefulness as doing something as a means to gain wider benefits or outcomes), attainment value (the importance or value an activity has through affirming a personal or collective identity) and cost value (such as financial and emotional costs as well as time and other aspects) (Eccles 2009). Students' interest and utility have 
received the most attention within research studies and have closely associated with students' choices (Bates et al. 2009; Bøe and Henriksen 2013; Vidal Rodeiro 2007).

Alternate theoretical perspectives and numerous other factors can also be conceptualised and considered. For example, the theory of planned behaviour proposes that intentions/choices follow from someone's confidence and subjective values and also from social norms or other pressure, guidance or advice (Ajzen 1991). Students' science intentions and choices have indeed associated with advice and encouragement from various sources, although at varying and sometimes low magnitudes (Archer et al. 2015a; DeWitt et al. 2016). Students have infrequently mentioned that influences from other people were relevant to their choices (Holmegaard et al. 2014), although some students have cited a lack of support and encouragement as a reason, together with other reasons, for not studying science (Aschbacher et al. 2010).

\section{Profiles of Students' Attitudes and Beliefs}

Given the importance of students' attitudes within motivational theories, research has sought to reveal naturally occurring clusters of students, which may help describe those students who may or may not intend to study science, which may help suggest foci for interventions.

In the USA, various studies of secondary school students have considered students' attitudes and beliefs (often focusing on their confidence/expectations, interest value and utility value from the expectancy-value model) and have identified distinct clusters of students, each with broadly proportionate attitudes and beliefs, such as these being generally high, moderate or low in magnitude (Andersen and Chen 2016; Andersen and Cross 2014; Chow et al. 2012; Conley 2012; Simpkins and Davis-Kean 2005). When further characteristics of students have been considered, boys have been more likely to be classified into clusters with generally high beliefs, while girls have been more likely to be classified into clusters with generally low beliefs (Chow et al. 2012; Simpkins and Davis-Kean 2005). When students' intentions or choices were also considered, students in clusters with consistently high beliefs were associated with studying more science and mathematics courses (Simpkins and Davis-Kean 2005) and associated with higher aspirations towards science careers (Chow et al. 2012). Essentially, holding high confidence/expectations and also high subjective values (interest value and utility value) associated with higher science intentions compared to other naturally emerging combinations (Simpkins and Davis-Kean 2005).

Few comparable studies appear to have been undertaken in England. Quantitative studies considering students' attitudes and beliefs about science have generally considered samples of students as a whole (e.g. DeWitt and Archer 2015), although qualitative studies have highlighted the plausibility of different students holding different profiles of beliefs, considered as varying combinations of science aspirations, attainment, interest and other factors (e.g. Wong 2016). Specific research into the area may therefore offer new insights.

\section{Research Aims}

Research has highlighted that students' attitudes and beliefs are especially relevant to their intentions to study science, particularly their interest in science and their perceived utility of science (Bøe and Henriksen 2015; Regan and DeWitt 2015). Research has also begun to reveal and consider clusters of students, given their various attitudes to science such as their interest and perceived utility (Andersen and Chen 2016; Chow et al. 2012). 
Considering clusters of students in England could help quantify proportions of students who might or might not intend to study physics and reveal their wider profiles of attitudes. Research could then also determine whether and/or how these proportions and profiles change over time, ultimately offering new knowledge for the field of science education within England and insights for those working within other countries.

Accordingly, the aims of this study were to (1) confirm key predictors of students' intentions to study upper-secondary physics; (2) determine what clusters of students emerged, given the key predictors, and determine how students' intentions varied across any clusters; and (3) determine changes in cluster membership over time.

\section{Methods}

\section{Sample}

Schools across England were sampled within categories of physics attainment and progression (above-average/below-average cross-tabulations), given national records from the Department for Education, and those with above-average attainment/ progression were also intentionally over-sampled. The sampling concurrently ensured coverage of schools with various admissions policies and other typologies. Within schools, data collection targeted students expected to attain grades from $A^{*}$ to $D$ in GCSE physics (approximately the top two thirds of students). This sampling/targeting was intended to facilitate insight into those students who might potentially study noncompulsory physics.

The analysis considered a longitudinal sample of 2258 physics students, surveyed in year 8 (age 12/13) in 2009 and again in year 10 (age 14/15) in 2011. This cohort covered 88 schools with broad geographical coverage: $3 \%$ in the East Midlands, $13 \%$ in the East, $17 \%$ in London, $8 \%$ in the North East, $9 \%$ in the North West, $26 \%$ in the South East, $7 \%$ in the South West, $10 \%$ in the West Midlands and $7 \%$ in Yorkshire and the Humber. Across the schools, 9\% were boys-only, 21\% were girls-only and $70 \%$ were mixed; concurrently, $13 \%$ required prior attainment for admissions (selective schools, also known as grammar schools) while $87 \%$ did not. For contextualisation, as of 2008 (the original national sampling frame for the study), across the 4145 secondary schools with students taking GCSEs across England, 7\% were boys-only, $12 \%$ were girls-only and $81 \%$ were mixed; $18 \%$ required prior attainment for admissions while $82 \%$ did not. Currently, as of 2017, across the 5393 secondary schools with students taking GCSEs across England, 6\% are boysonly, $7 \%$ are girls-only and $87 \%$ are mixed; only $5 \%$ require prior attainment for admissions while the others do not or their admissions information is not available (Department for Education 2017).

\section{Student Questionnaires}

Students completed physics-specific questionnaires in year 8 and again in year 10. The various items/factors were informed by the established measurement of various attitudes and beliefs within the expectancy-value model of choices and other theoretical/motivational perspectives (Bøe and Henriksen 2015; Eccles 2009; Wigfield and Cambria 2010). 
The assignment of items to factors was verified through confirmatory factor analysis (factor by factor) and through exploratory factor analysis (considering emergent factors from all available items). The factors showed acceptable reliability (internal consistency) measured via Cronbach's $\alpha$ (alpha) coefficients (as noted below). Factors were calculated as the average of the relevant individual items, reverse-scoring items when necessary to maintain consistency (i.e. higher factor-scores reflected higher interest, utility, etc.). The factors then reflected the underlying agreement scale from (1) Strongly disagree, (2) Disagree, (3) Slightly disagree, (4) Slightly agree, (5) Agree, to (6) Strongly agree.

Factors were formed following prior research and operationalisations of the expectancy-value model (Bøe and Henriksen 2015). Specifically, students' confidence/expectations were measured as self-concept beliefs (4 items, e.g. "I am good at physics", "I do well in physics tests"; year 8 $\alpha=0.829$, year $10 \alpha=0.848$ ). Subjective values regarding science were separately measured as interest value (3 items, e.g. "Physics is interesting", "In physics, it is interesting to find out about the laws that explain different phenomena"; year $8 \alpha=0.850$, year $10 \alpha=0.871$ ) and utility value (8 items, e.g. "I think physics will help me in the job I want to do in the future", "These days, everybody needs to know some physics"; year $8 \alpha=0.844$, year $10 \alpha=0.796$ ).

In order to potentially gain insight through supplementing the expectancy-value model with the planned behaviour model (Ajzen 1991), two separate aspects of social norms and guidance were measured: the students' perceived advice, guidance and/or suggestions from teachers, parents and friends (4 items, e.g. "My teacher thinks that I should continue with physics beyond my GCSEs"; year $8 \alpha=0.832$, year 10 $\alpha=0.796$ ); and the students' perceived home support for physics (5 items, e.g. "Someone in my family wants me to be successful at school in physics", "Someone in my family thinks that anyone can do physics if they try hard enough"; year 8 $\alpha=0.845$, year $10 \alpha=0.760$ ).

Students' aspirations or intentions to study upper-secondary (non-compulsory) physics were also measured (i.e. the extent of agreement/disagreement with "I intend to continue to study physics after my GCSEs"). Additionally, students' background was measured through their gender, their ethnicity and their highest parental occupation (via students selecting ranked categories with example occupations given for illustration, reflecting ideas of socio-economic statuses). Students' prior science attainment was also measured, as of Key Stage 2 (year 6, the end of primary school), as it was unfeasible to burden teachers/schools by requests for detailed contemporary attainment records.

\section{Analytical Approaches}

The analysis focused on students' reported experiences and beliefs for consistency and given their centrality within motivational theories (Bøe and Henriksen 2015; Eccles 2009). Considering wider contextual indicators or influences (e.g. school features and policies) remained outside of the current research aims and scope. Across the analysis, the standard criterion $(p<.05)$ was used for statistical significance.

\section{Missing Responses/Values}

Statistical analysis such as predictive modelling only considers those students with responses/scores for every item/factor: even though all 2258 students participated on 
both occasions, only 1686 students at year 8 and 1379 students at year 10 responded to all of the considered questionnaire items; the others still answered the majority of the questions, but they left at least one question blank. Considering fewer students reduces the power of statistical tests to reveal significant differences. In a longitudinal design, it is also beneficial to consistently consider the same students.

Accordingly, estimates of missing values/scores were produced using full-information maximum-likelihood via expectation-maximisation, which is considered one of the best approaches to handling missing data (IBM 2014; Peugh and Enders 2004). Estimates could not be produced for binary/categorical indicators, however, so an 'unknown' category was included for missing ethnicity; there were no missing gender indicators. This allowed all 2258 students to be consistently considered, regardless of the type of analysis (e.g. predictive modelling, cluster analysis, etc.) and/or the number of items/ factors being modelled.

Preliminary analysis highlighted that the same results/conclusions emerged regardless of whether missing values/scores were estimated or not. The presented results include estimates of missing values/scores in order to maximise the considered student numbers and maintain the consistent longitudinal sample.

\section{Predictive Modelling}

Preliminary analysis applied single-level linear regression (via ordinary least-squares estimation) and also multi-level linear regression (via maximum-likelihood estimation with variable intercepts per school) to account for students being grouped within schools (Snijders and Bosker 2012). The presented results report on multi-level linear regression, given that there was some (although minimal) residual variance across schools; the parameter estimates were similar across approaches, regardless. The predictive associations ('effect sizes') were reported as standardised coefficients: how many standard deviations of increase/decrease would occur in the outcome, given one standard deviation increase in the predictor.

\section{Cluster Analysis}

Cluster analysis (a generic term encompassing various methods) aims to identify naturally occurring clusters of students who have similar patterns of responses for the considered items/factors. Ideally, homogenous clusters will be formed (within each cluster, the students have similar patterns of responses) which are clearly separate from one another (different patterns of responses are characteristic of different clusters) (Collins and Lanza 2010; Everitt et al. 2011). The patterns of responses (profiles) and sizes of any clusters empirically depend on the data.

Given the longitudinal design, the cluster analysis was undertaken through latent-transition analysis via Markov models. Details of the method and illustrated examples are available in handbooks (Collins and Lanza 2010, pp. 187-224) and in more technical material (Vermunt and Magidson 2016, pp. 91-95). Expressed briefly, the modelling revealed equivalent clusters at year 8 and year 10 (by concurrently considering both time points) and modelled any transition of students across the clusters over time (by considering the students' probability of cluster membership at each time point, and so considering their probability of remaining within a cluster or transitioning to a different cluster). 
Latent-transition analysis is considered one of the best contemporary approaches to cluster analysis (preferable to approaches such as hierarchical or optimisation clustering methods), and also provides indicators that help determine which number(s) of clusters give good fit to the data (Collins and Lanza 2010; Everitt et al. 2011; Vermunt and Magidson 2016). Nevertheless, latent-transition analysis applies maximum-likelihood estimation, which may allow various 'locally-optimal' solutions to be found rather than one single globally-optimal solution (Collins and Lanza 2010). An extensive number of starting values (i.e. 1000) were therefore applied during estimation for each model; each set of models (i.e. 1-10 clusters) was itself re-estimated 10 times to consider and confirm the consistency of the results (Vermunt and Magidson 2016).

As further checks, preliminary analysis applied various other approaches (such as clustering via latent-profile analysis separately at each time point), which produced broadly similar cluster profiles. The presented results report on the latent-transition analysis, given that this approach is considered preferable for longitudinal data (Collins and Lanza 2010).

\section{Results}

\section{Sample Summary}

Across the sample (Table 1), the students' attitudes and beliefs showed varying degrees of change from year 8 to year 10. This included the students, on average, expressing lower intentions towards studying physics at year 10, but expressing higher perceived advice, perceptions of the utility of physics and home support for physics at year 10 .

At year 8 (Table 2) and year 10 (Table 3), the students' physics intentions most strongly correlated with their self-concept beliefs, intrinsic value, utility value, perceived advice and home support for physics. These factors also had the highest (moderate to large) correlations between each other.

\section{Predictive Modelling}

Predicting students' physics intentions using their background characteristics (gender, prior attainment, parental occupation and ethnicity) only explained $1.9 \%$ of the variance at year 8 and $7.3 \%$ at year 10 (not tabulated for brevity). At year 8 , significant predictors were gender (being male compared to female, standardised coefficient $(\beta)=0.100, p<.001$ ), prior attainment $(\beta=0.061, p=.006$ ) and ethnicity (being South-Asian/Indian compared to white, $\beta=0.048, p=.044$; being East-Asian/Chinese compared to white, $\beta=0.061, p=.004)$. At year 10, significant predictors were gender (being male, $\beta=0.264, p<.001$ ) and ethnicity (being South-Asian/Indian compared to white, $\beta=0.063, p=.007$ ).

Predicting students' physics intentions using their background characteristics and also using the theorised factors from the expectancy-value and planned-behaviour models (self-concept beliefs, interest value, utility value, advice and home support) explained more variance (46.6\% at year 8 and $47.3 \%$ at year 10 ; Table 4 ). The expectancy-value and planned-behaviour factors associated with students' intentions at year 8 and at year 10 , and these factors essentially mediated or explained the differences in intentions 
Table 1 Sample summary

\begin{tabular}{|c|c|c|c|c|c|c|c|c|}
\hline \multirow[b]{2}{*}{ Items/factors (1-6 scales unless noted) } & \multicolumn{2}{|l|}{ Year 8} & \multicolumn{2}{|c|}{ Year 10} & \multicolumn{2}{|c|}{$\begin{array}{l}\text { Year 8-10 mean } \\
\text { difference }\end{array}$} & \multicolumn{2}{|c|}{$\begin{array}{l}\text { Year 8-10 } \\
\text { correlation }\end{array}$} \\
\hline & M & $\mathrm{SD}$ & M & $\mathrm{SD}$ & $\mathrm{D}$ & Sig. & $R$ & Sig. \\
\hline Gender (1 = boy) & 0.44 & 0.50 & 0.44 & 0.50 & NA & NA & NA & NA \\
\hline Prior science attainment $(0-100)$ & 82.41 & 10.28 & 82.41 & 10.28 & NA & NA & NA & NA \\
\hline Parental occupation status $(1-10)$ & 8.20 & 2.44 & 8.20 & 2.44 & NA & NA & NA & NA \\
\hline Ethnicity (1 = white) & 0.79 & 0.41 & 0.79 & 0.41 & NA & NA & NA & NA \\
\hline Ethnicity ( 1 = South-Asian/Indian) & 0.08 & 0.28 & 0.08 & 0.28 & NA & NA & NA & NA \\
\hline Ethnicity $(1$ = black $)$ & 0.02 & 0.15 & 0.02 & 0.15 & NA & NA & NA & NA \\
\hline Ethnicity ( 1 = East-Asian/Chinese) & 0.01 & 0.11 & 0.01 & 0.11 & NA & NA & NA & NA \\
\hline Ethnicity $(1=$ mixed $)$ & 0.03 & 0.18 & 0.03 & 0.18 & NA & NA & NA & NA \\
\hline Ethnicity (1 = unknown) & 0.06 & 0.23 & 0.06 & 0.23 & NA & NA & NA & NA \\
\hline Intentions & 3.72 & 1.46 & 3.47 & 1.50 & 0.147 & $<.001$ & .325 & $<.001$ \\
\hline Self-concept & 3.88 & 1.03 & 3.86 & 1.08 & 0.019 & .369 & .441 & $<.001$ \\
\hline Interest value & 3.91 & 1.31 & 3.83 & 1.36 & 0.056 & .008 & .389 & $<.001$ \\
\hline Utility value & 4.08 & 0.90 & 4.30 & .83 & 0.217 & $<.001$ & .358 & $<.001$ \\
\hline Advice & 3.55 & 1.42 & 3.72 & 1.19 & 0.105 & $<.001$ & .265 & $<.001$ \\
\hline Home support for physics & 4.22 & 1.17 & 4.43 & .96 & 0.172 & $<.001$ & .384 & $<.001$ \\
\hline Students (number, \%) & 2258 & $100 \%$ & 2258 & $100 \%$ & & & & \\
\hline
\end{tabular}

Missing responses were estimated by expectation-maximisation. Means ('M') and standard deviations ('SD') are reported. Mean differences from year 8 to year 10 (paired sample $t$ tests) show the absolute magnitude ('D'; Cohen's $d$ ) and significance ('Sig.'; $p$ values). Correlations between year 8 and year 10 responses show Pearson correlations coefficients $(R)$ and significance ('Sig.'; $p$ values). Significant values $(p<.05)$ are highlighted in italics

initially associated with students' ethnicity. Nevertheless, the students' gender was still predictive when considered longitudinally and when considered at year 10 (Table 4). Perhaps most importantly, the expectancy-value and planned-behaviour factors reported at year 8 were positive predictors of the students' subsequent intentions reported at year 10 , with the exception of reported advice (Table 4). Nevertheless, reported advice was still predictive at year 8 and at year 10 when considered in the cross-sectional models (Table 4).

Essentially, the predictive modelling empirically confirmed the relevance of students' selfconcept beliefs, interest value, utility value, advice and home support, and hence that considering clusters of students using these factors may offer insights.

\section{Cluster Analysis}

The latent-transition analysis via Markov models considered students' physics expectancy/ confidence (self-concept beliefs), interest value of physics, utility value of physics, advice to study physics and home support for physics, reported at year 8 and at year 10 .

The results highlighted increasing (but diminishing) improvements in the model information criteria (which reflected 'fit to the data') as the number of modelled clusters increased (Table 5). This indicated that considering multiple clusters rather than one single cluster (the entire sample) was an empirically validated approach.

Modelling one to six clusters produced stable and consistent results across multiple starting values and replications, providing plausible support for these being globally-optimal solutions to explain the data given these particular numbers of clusters (Collins and Lanza 2010; Everitt et al. 2011). Despite multiple replications, modelling seven or more clusters produced varying 


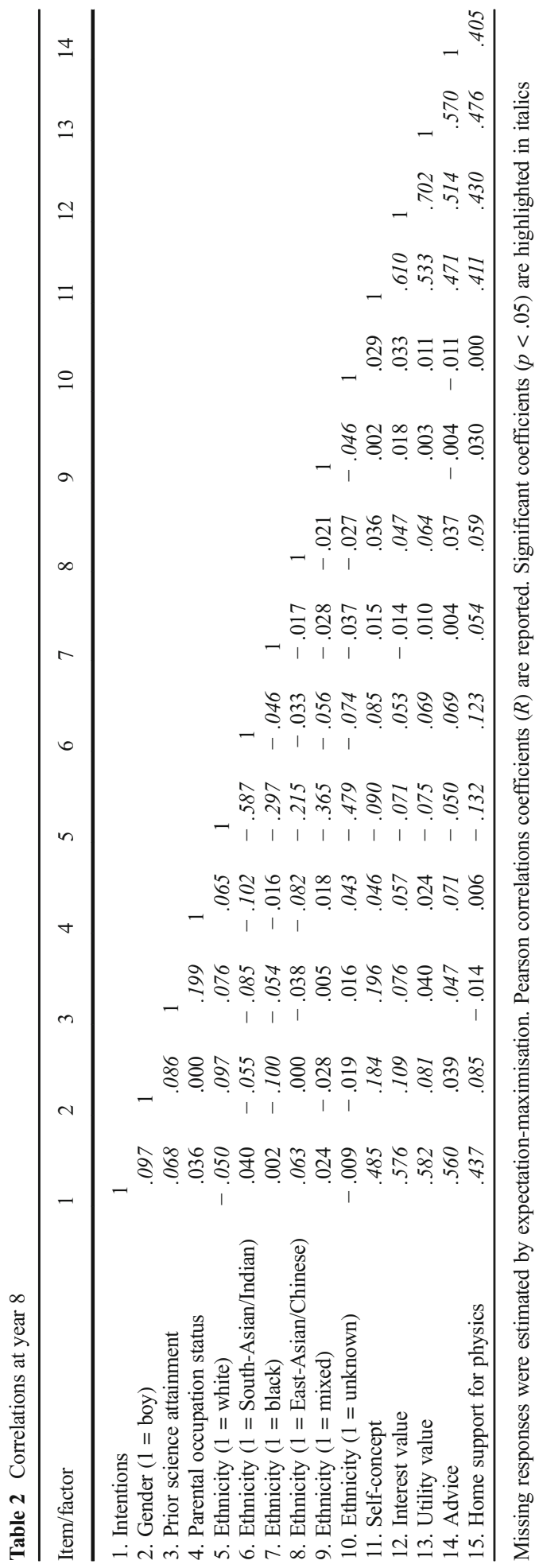




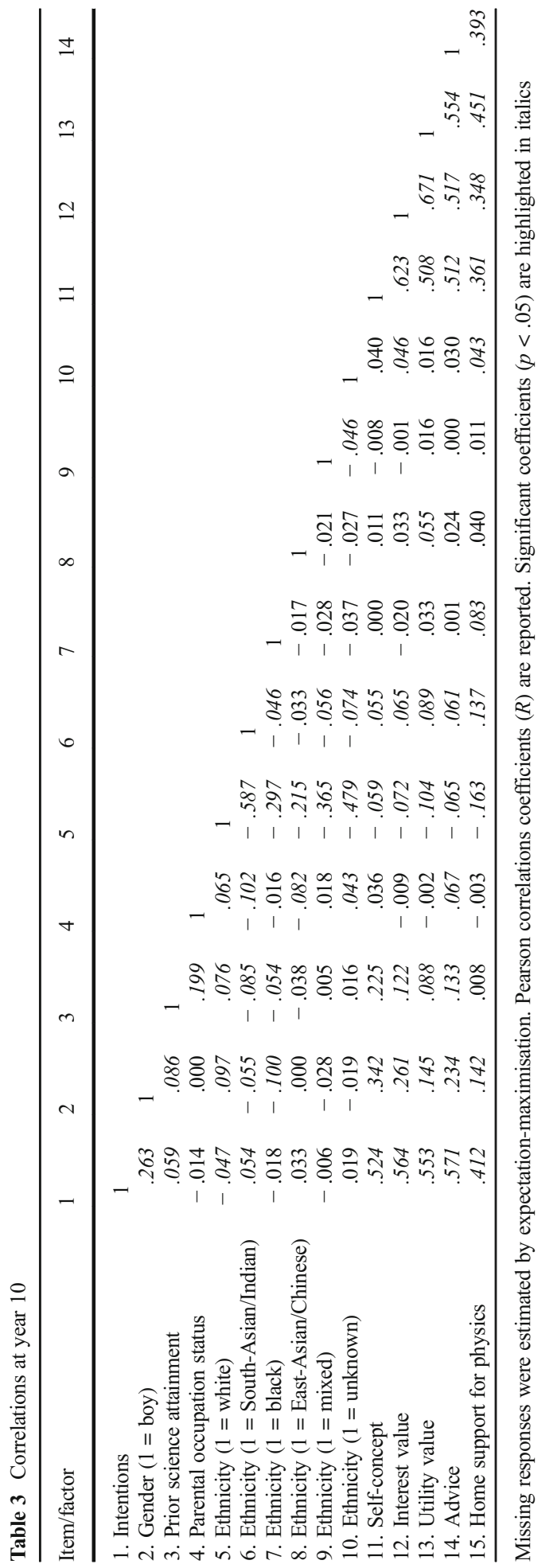


Table 4 Predicting students' physics studying intentions

\begin{tabular}{|c|c|c|c|c|c|c|}
\hline \multirow[b]{2}{*}{ Item/factor } & \multicolumn{2}{|c|}{$\begin{array}{l}\text { Model 1: year } 8 \text { items/ } \\
\text { factors predicting year } 8 \\
\text { intentions }\end{array}$} & \multicolumn{2}{|c|}{$\begin{array}{l}\text { Model 2: year } 8 \text { items/ } \\
\text { factors predicting year } \\
10 \text { intentions }\end{array}$} & \multicolumn{2}{|c|}{$\begin{array}{l}\text { Model 3: year } 10 \text { items/ } \\
\text { factors predicting year } \\
10 \text { intentions }\end{array}$} \\
\hline & Std. effect & Sig. & Std. effect & Sig. & Std. effect & Sig. \\
\hline Intercept/constant & $N A$ & .005 & $N A$ & $<.001$ & $N A$ & .020 \\
\hline Gender (1 = boy) & .017 & .297 & .221 & $<.001$ & .069 & $<.001$ \\
\hline Prior science attainment & .016 & .341 & .015 & .493 & -.056 & .001 \\
\hline Parental occupation status & -.006 & .708 & -.028 & .157 & -.025 & .111 \\
\hline Ethnicity (South-Asian/Indian) & -.016 & .367 & .037 & .102 & -.015 & .400 \\
\hline Ethnicity (Black) & -.004 & .815 & -.003 & .899 & -.029 & .066 \\
\hline Ethnicity (East-Asian/Chinese) & .018 & .262 & .012 & .532 & .007 & .668 \\
\hline Ethnicity (Mixed) & .015 & .340 & -.006 & .751 & -.009 & .555 \\
\hline Ethnicity (Unknown) & -.018 & .293 & .028 & .210 & .003 & .867 \\
\hline Self-concept & .087 & $<.001$ & .081 & .002 & .147 & $<.001$ \\
\hline Interest value & .209 & $<.001$ & .099 & .001 & .192 & $<.001$ \\
\hline Utility value & .184 & $<.001$ & .075 & .012 & .148 & $<.001$ \\
\hline Advice & .259 & $<.001$ & .040 & .111 & .259 & $<.001$ \\
\hline Home support for physics & .118 & $<.001$ & .068 & .003 & .116 & $<.001$ \\
\hline Explained variance & $46.6 \%$ & & $15.1 \%$ & & $47.3 \%$ & \\
\hline Unexplained variance (residual) & $52.1 \%$ & & $81.8 \%$ & & $50.7 \%$ & \\
\hline Unexplained variance (school) & $1.3 \%$ & & $3.2 \%$ & & $1.9 \%$ & \\
\hline
\end{tabular}

Missing responses were estimated by expectation-maximisation. Standardised coefficients ('Std. effect') and significance ('Sig.'; $p$ values) are reported. Significant coefficients $(p<.05)$ are highlighted in italics. Ethnicity categories reflect comparisons against 'white' students

solutions (these results could potentially be one of many 'locally-optimal solutions' given a number of clusters).

Focusing on particular numbers of clusters often (pragmatically) balances the fit to the data with interpretability, differences across solutions and the cluster sizes (Collins and Lanza 2010). Higher numbers of clusters may offer increasingly diminishing returns in exchange for greater complexity; smaller numbers of clusters may offer practical insight through being easy to interpret. For this study, the relative improvement in model fit from three to four clusters was higher than the improvement from four to five clusters or from five to six clusters,

Table 5 Cluster model fit summary

\begin{tabular}{lllc}
\hline Clusters & $\begin{array}{l}\text { Bayesian information } \\
\text { criteria }\end{array}$ & $\begin{array}{l}\text { Akaike information } \\
\text { criteria }\end{array}$ & $\begin{array}{l}\text { Sample-size adjusted Bayesian } \\
\text { information criteria }\end{array}$ \\
\hline 1 & $69,106.79$ & $69,049.57$ & $69,075.02$ \\
2 & $62,284.10$ & $62,152.49$ & $62,211.02$ \\
3 & $60,013.13$ & $59,795.68$ & $59,892.40$ \\
4 & $58,869.65$ & $58,554.92$ & $58,694.90$ \\
5 & $58,320.62$ & $57,897.18$ & $58,085.51$ \\
6 & $58,039.86$ & $57,496.25$ & $57,738.03$ \\
7 & L $57,822.62$ & L $57,147.40$ & L $57,447.72$ \\
8 & L $57,274.20$ & L $56,455.92$ & L $56,819.86$ \\
9 & L $57,535.88$ & L $56,563.10$ & L $56,995.76$ \\
10 & L $56,756.16$ & & $56,123.90$ \\
\hline
\end{tabular}

Missing responses were estimated by expectation-maximisation. Lower information criteria reflect better fit to the data. Information criteria marked with an 'L' report the lowest achieved result but without confirmation through replications (these could be a locally-optimal solution, not necessarily a global solution) 
suggesting that considering four clusters might balance model fit with an easily interpretable number of clusters; however, some similarities in responses were observed across two of the clusters within the four-cluster models, suggesting that one of these clusters might be an exceptional (and small) case that was otherwise similar the other. One cluster was also similarly identified in both the four-cluster and the five-cluster solutions, while three clusters were similarly identified in both the five-cluster and six-cluster solutions.

Prior research has most frequently considered three or four clusters or groups (e.g. Andersen and Chen 2016; Archer et al. 2015a; Simpkins and Davis-Kean 2005), and preliminary analysis considered the three-cluster, four-cluster and five-cluster models in detail. Similar trends were seen across these models, regardless of the different numbers of clusters, highlighting that the research questions could be most efficiently answered by the three-cluster models: further numbers of clusters offered insight, but with increasing numbers of smaller clusters that might be harder to generalise from. For comprehensiveness, results from the threecluster, four-cluster and five-cluster models have been fully detailed in the Supplementary Material (Supplementary Material: Appendix A, Appendix B and Appendix C), while (for brevity) the three-cluster models and the common trends are summarised in the following sections.

To aid interpretation, the clusters were labelled in order of descending attitudes and beliefs, with 'cluster A' reflecting the highest (most positive) attitudes.

\section{Three-Cluster Models}

The three-cluster models are summarised here for brevity and ease of interpretation, and given the similar trends observed across the three-cluster, four-cluster and five-cluster models (Supplementary Material: Appendix A, Appendix B and Appendix C). The overall numbers of students per cluster per year (Table 6) and cluster profiles at year 8 (Table 7) and year 10 (Table 8 ) are presented here, while the paired differences between the clusters (via Bonferroni post hoc tests) are appended for brevity (Supplementary Material: Appendix A).

The cluster profiles revealed (Tables 7 and 8): one cluster with generally positive responses, around 5 on the 1-6 scales for their interest value of physics, utility value of physics, advice to study physics and home support for physics (cluster A: $20.5 \%$ of the sample at year 8 and $24.7 \%$ at year 10 ); another cluster with slightly positive responses, around 4 on the 1-6 scales (cluster B: $52.0 \%$ at year 8 and $49.8 \%$ at year 10 ); and another cluster with ambivalent to negative responses, responding close to or below the 3.5 mid-point of the $1-6$ scales (cluster $\mathrm{C}$ : $27.5 \%$ at year 8 and $25.5 \%$ at year 10 ). There was generally less within-cluster variability for each item/factor (seen via the standard deviations) and smaller overall range of responses

Table 6 Three-cluster model

\begin{tabular}{|c|c|c|c|c|c|c|c|c|}
\hline \multirow[t]{2}{*}{ Year 10 membership } & \multicolumn{6}{|c|}{ Year 8 membership } & \multirow[t]{2}{*}{ Total } & \\
\hline & A & & $\mathrm{B}$ & & $\mathrm{C}$ & & & \\
\hline $\mathrm{A}$ & 312 & $67.4 \%$ & 200 & $17.0 \%$ & 46 & $7.4 \%$ & 558 & $24.7 \%$ \\
\hline B & 121 & $26.1 \%$ & 754 & $64.2 \%$ & 250 & $40.3 \%$ & 1125 & $49.8 \%$ \\
\hline $\mathrm{C}$ & 30 & $6.5 \%$ & 220 & $18.7 \%$ & 325 & $52.3 \%$ & 575 & $25.5 \%$ \\
\hline Total & 463 & $100.0 \%$ & 1174 & $100.0 \%$ & 621 & $100.0 \%$ & 2258 & $100.0 \%$ \\
\hline
\end{tabular}

Percentages are reported from the year 8 cluster membership ('column' percentages) 
Table 7 Three-cluster model profiles at year 8

\begin{tabular}{|c|c|c|c|c|c|c|c|c|}
\hline \multirow[t]{2}{*}{ Items/factors (1-6 scales unless noted) } & \multicolumn{2}{|l|}{ A } & \multicolumn{2}{|l|}{$\mathrm{B}$} & \multicolumn{2}{|l|}{$\mathrm{C}$} & \multicolumn{2}{|c|}{ ANOVA } \\
\hline & M & $\mathrm{SD}$ & M & SD & M & SD & Sig. & $\mathrm{Eta}^{2}$ \\
\hline Gender (1 = boy) & 0.58 & 0.49 & 0.43 & 0.49 & 0.37 & 0.48 & $<.001$ & 0.022 \\
\hline Prior science attainment $(0-100)$ & 84.04 & 10.02 & 82.41 & 10.27 & 81.19 & 10.33 & $<.001$ & 0.009 \\
\hline Parental occupation status $(1-10)$ & 8.40 & 2.51 & 8.21 & 2.39 & 8.03 & 2.47 & .047 & 0.003 \\
\hline Ethnicity $(1=$ White $)$ & 0.73 & 0.45 & 0.80 & 0.40 & 0.83 & 0.37 & $<.001$ & 0.008 \\
\hline Ethnicity ( 1 = South-Asian/Indian) & 0.12 & 0.32 & 0.08 & 0.28 & 0.05 & 0.22 & .001 & 0.007 \\
\hline Ethnicity (1 = Black) & 0.03 & 0.17 & 0.02 & 0.14 & 0.02 & 0.14 & .461 & 0.001 \\
\hline Ethnicity ( 1 = East-Asian/Chinese) & 0.02 & 0.15 & 0.01 & 0.10 & 0.01 & 0.09 & .031 & 0.003 \\
\hline Ethnicity $(1=$ Mixed $)$ & 0.04 & 0.20 & 0.03 & 0.17 & 0.04 & 0.19 & .409 & 0.001 \\
\hline Ethnicity (1 = Unknown) & 0.06 & 0.23 & 0.06 & 0.24 & 0.05 & 0.21 & .562 & 0.001 \\
\hline Intentions & 5.02 & 1.01 & 3.87 & 1.19 & 2.48 & 1.20 & $<.001$ & 0.369 \\
\hline Self-concept & 4.88 & 0.62 & 4.01 & 0.66 & 2.89 & 1.01 & $<.001$ & 0.453 \\
\hline Interest value & 5.34 & 0.53 & 4.16 & 0.75 & 2.38 & 0.98 & $<.001$ & 0.643 \\
\hline Utility value & 5.06 & 0.46 & 4.20 & 0.53 & 3.15 & 0.80 & $<.001$ & 0.550 \\
\hline Advice & 4.97 & 0.74 & 3.69 & 1.14 & 2.24 & 1.11 & $<.001$ & 0.443 \\
\hline Home support for physics & 5.28 & 0.59 & 4.23 & 0.95 & 3.41 & 1.25 & $<.001$ & 0.298 \\
\hline Students (number, \%) & 463 & $20.5 \%$ & 1174 & $52.0 \%$ & 621 & $27.5 \%$ & & \\
\hline
\end{tabular}

Missing responses were estimated by expectation-maximisation. Means ('M') and standard deviations ('SD') are reported. Analysis of variance (ANOVA) tests highlighted mean differences across the clusters; significance ('Sig.'; p values) and magnitude ('Eta ${ }^{2}$ '; eta-squared) are reported. Significant values $(p<.05)$, reflecting mean differences across the clusters, are highlighted in italics

(from the relatively lowest to the relatively highest within-cluster responses) for cluster $\mathrm{A}$ and more variability/range for cluster C (Tables 7 and 8). For example, at year 10 for those in cluster A, responses ranged from positive intentions towards studying physics (mean (M) on

Table 8 Three-cluster model profiles at year 10

\begin{tabular}{|c|c|c|c|c|c|c|c|c|}
\hline \multirow[t]{2}{*}{ Items/factors (1-6 scales unless noted) } & \multicolumn{2}{|l|}{ A } & \multicolumn{2}{|l|}{ B } & \multicolumn{2}{|l|}{$\mathrm{C}$} & \multicolumn{2}{|c|}{ ANOVA } \\
\hline & M & SD & M & $\mathrm{SD}$ & M & SD & Sig. & $\mathrm{Eta}^{2}$ \\
\hline Gender (1 = boy) & 0.64 & 0.48 & 0.44 & 0.50 & 0.26 & 0.44 & $<.001$ & 0.074 \\
\hline Prior science attainment $(0-100)$ & 84.62 & 9.33 & 82.45 & 10.22 & 80.18 & 10.79 & $<.001$ & 0.023 \\
\hline Parental occupation status $(1-10)$ & 8.26 & 2.48 & 8.19 & 2.45 & 8.16 & 2.40 & .781 & $<0.001$ \\
\hline Ethnicity (1 = White) & 0.73 & 0.45 & 0.80 & 0.40 & 0.83 & 0.37 & $<.001$ & 0.010 \\
\hline Ethnicity ( 1 = South-Asian/Indian) & 0.12 & 0.32 & 0.08 & 0.27 & 0.05 & 0.22 & $<.001$ & 0.008 \\
\hline Ethnicity $(1=$ Black $)$ & 0.03 & 0.16 & 0.02 & 0.15 & 0.02 & 0.14 & .785 & $<0.001$ \\
\hline Ethnicity ( 1 = East-Asian/Chinese $)$ & 0.02 & 0.15 & 0.01 & 0.09 & 0.01 & 0.08 & .017 & 0.004 \\
\hline Ethnicity $(1=$ Mixed $)$ & 0.04 & 0.19 & 0.03 & 0.16 & 0.04 & 0.20 & .215 & 0.001 \\
\hline Ethnicity (1 = Unknown) & 0.07 & 0.26 & 0.06 & 0.23 & 0.05 & 0.21 & .149 & 0.002 \\
\hline Intentions & 4.80 & 1.10 & 3.45 & 1.23 & 2.23 & 1.19 & $<.001$ & 0.370 \\
\hline Self-concept & 4.87 & 0.69 & 3.94 & 0.69 & 2.72 & 0.94 & $<.001$ & 0.503 \\
\hline Interest value & 5.30 & 0.56 & 3.93 & 0.86 & 2.20 & 0.87 & $<.001$ & 0.655 \\
\hline Utility value & 5.16 & 0.42 & 4.30 & 0.50 & 3.45 & 0.79 & $<.001$ & 0.527 \\
\hline Advice & 4.81 & 0.66 & 3.76 & 0.94 & 2.57 & 0.99 & $<.001$ & 0.442 \\
\hline Home support for physics & 5.17 & 0.59 & 4.37 & 0.78 & 3.81 & 1.07 & $<.001$ & 0.257 \\
\hline Students (number, \%) & 558 & $24.7 \%$ & 1125 & $49.8 \%$ & 575 & $25.5 \%$ & & \\
\hline
\end{tabular}

Missing responses were estimated by expectation-maximisation. Means ('M') and standard deviations ('SD') are reported. Analysis of variance (ANOVA) tests highlighted mean differences across the clusters; significance ('Sig.'; p values) and magnitude ('Eta ${ }^{2}$ '; eta-squared) are reported. Significant values $(p<.05)$, reflecting mean differences across the clusters, are highlighted in italics 
the $1-6$ scale $=4.80)$ to slightly higher positive interest in physics $(M=5.30)$, essentially with a range of 0.5 agreement-scale points. At year 10 for those in cluster $\mathrm{C}$, responses ranged from negative interest in physics ( $\mathrm{M}=2.20$, i.e. below the 3.5 scale mid-point) to more ambivalent but slightly positive home support for physics $(M=3.81)$, essentially with a range of just over 1.6 agreement-scale points.

Considering the three clusters revealed average across-cluster differences in physics intentions at year 8 (Table $\left.7 ; F(2,2255)=660.687, p<.001, \eta^{2}=0.369\right)$ and year 10 (Table $\left.8 ; F(2,2255)=663.122, p<.001, \eta^{2}=0.370\right)$. When also controlling for the factors used in the cluster formation (students' physics self-concept beliefs, interest value of physics, utility value of physics, advice to study physics and home support for physics), across-cluster differences in physics intentions at year 8 were non-significant $\left(F(2,2250)=0.819, p=.441, \eta^{2}=0.001\right)$ but remained at year 10 although at a low magnitude $\left(F(2,2250)=4.116, p=.016, \eta^{2}=0.003\right)$. Fundamentally, at year 10 (Table 8), only those in cluster A expressed agreement to study physics further $(\mathrm{M}=4.80)$ while those in cluster $\mathrm{B}$ were ambivalent $(\mathrm{M}=3.45)$ and those in cluster $\mathrm{C}$ expressed disagreement to study physics further $(\mathrm{M}=2.23)$.

Considering aggregated changes in cluster membership (the sum of the relevant cells in Table 6), 496 students (22.0\% of the entire sample) moved into a cluster with more-positive attitudes and beliefs (i.e. moving from cluster B to A, from C to B, or from C to A), 1391 $(61.6 \%)$ remained in the same cluster over time and $371(16.4 \%)$ moved into a less-positive cluster. Additionally, a higher proportion of students remained within cluster A (where $67.4 \%$ of the original cluster membership from year 8 remained at year 10) than remained in cluster $\mathrm{C}$ (where $52.3 \%$ of the original cluster membership from year 8 remained at year 10).

Considering students' background characteristics (their gender, prior attainment, parental occupation and ethnicity), at year 8 (Table 7) and at year 10 (Table 8), the overall proportions of students per cluster varied by gender, prior attainment and ethnicity (but only varied by parental occupation at Year 8), and the differences were slightly higher at year 10 (e.g. the magnitude of the difference in gender proportions across the clusters was $\eta^{2}=0.022$ at year 8 and $\eta^{2}=0.074$ at year 10 ; Tables 7 and 8).

Specifically considering students' background characteristics (their gender, prior attainment, parental occupation and ethnicity) and transitions related to cluster A (the cluster with the most positive physics attitudes and the clearest agreement to study physics further) via analysis of variance (not tabulated for brevity), there were only differences between those 'staying' compared to those 'leaving' the cluster for gender (65.1\% male for those staying, $44.4 \%$ male for those leaving, $p<.001, \eta^{2}=0.039$ ) and prior science attainment (staying $\mathrm{M}=84.95$, leaving $\mathrm{M}=82.14, p=.005, \eta^{2}=0.017$ ). Further potential comparisons for other clusters, and/or any other potential sub-group analysis, remain as avenues for future research; nevertheless, these results clarified that some differences (such as the varying proportion of boys per cluster) slightly increased over time.

\section{Trends in Results}

Similar trends were observed across the three-cluster (Supplementary Material: Appendix A), four-cluster (Supplementary Material: Appendix B) and five-cluster (Supplementary Material: Appendix C) models. Specifically, across-cluster differences in physics intentions were significant at year 10 even when controlling for the factors used in the cluster formation for the three-cluster, four-cluster and five-cluster models. 
While most students remained within the same cluster over time, more students moved into a cluster with more-positive attitudes than moved into a cluster with less-positive attitudes and beliefs (Supplementary Material: Appendix A, Appendix B and Appendix C). In the threecluster models, 496 students $(22.0 \%$ of the entire sample) moved into a cluster with morepositive attitudes and beliefs, $1391(61.6 \%)$ remained in the same cluster over time and 371 $(16.4 \%)$ moved into a less-positive cluster. In the four-cluster models, 591 students $(26.2 \%)$ moved into a more-positive cluster, $1245(55.1 \%)$ remained in the same cluster over time and $422(18.7 \%)$ moved into a less-positive cluster. In the five-cluster models, 644 students $(28.5 \%)$ moved into a more-positive cluster, 1075 (47.6\%) remained in the same cluster over time and $539(23.9 \%)$ moved into a less-positive cluster.

Considering differences in transitions related to the cluster with the most positive attitudes and beliefs (cluster A) across students' background characteristics (gender, prior attainment, parental occupation and ethnicity), more boys than girls remained within cluster $\mathrm{A}$ in the threecluster, four-cluster and five-cluster models (Supplementary Material: Appendix A, Appendix $\mathrm{B}$ and Appendix C). There were also differences in transitions by prior attainment, where those with slightly higher prior attainment were more likely to remain in cluster A for the threecluster and four-cluster models (Supplementary Material: Appendix A and Appendix B). Some differences in transitions by ethnicity were observed, but only in the five-cluster models (Supplementary Material: Appendix C). No differences in transitions by parental occupation were observed. Nevertheless, further potential differences in transitions, and/or other potential sub-group analysis, remain as avenues for future research.

Within the four-cluster and five-cluster models (Supplementary Material: Appendix B and Appendix C), a small cluster of students was revealed (cluster D) who generally reported ambivalent to negative attitudes (such as for their interest in physics) but who also reported strong disagreement that they received any advice or encouragement to study physics (reporting the lowest possible responses on the scale at both year 8 and year 10, i.e. suggesting that they believed that they were strongly discouraged or advised not to study physics). This cluster was nevertheless small, encompassing $9.3 \%$ of the sample at year 8 and $3.5 \%$ of the sample at year 10, in both the four-cluster and five-cluster models, and exhibited some similar responses to the other clusters with ambivalent to negative attitudes.

\section{Discussion}

These findings offer various new insights for science education. Perceived advice, perceived utility of physics, interest in physics, self-concept beliefs (students' subjective beliefs of their current abilities and performance) and home support specifically orientated to physics were highlighted as key predictors of students' intentions to study upper-secondary physics (research aim 1 for the study). This helps refine theoretical and other perspectives that seek to identify and collate factors associated with students' studying intentions and choices, where the influence of advice is sometimes overlooked or assumed to only have an indirect influence (Bøe and Henriksen 2015). These results affirm that fostering students' attitudes and beliefs may be plausible approaches to help increase the number of students who study noncompulsory physics.

Latent-transition analysis via Markov models of these factors revealed distinct clusters of students (research aim 2), and common trends emerged regardless of whether the three-cluster, four-cluster or five-cluster models were considered. Students' physics attitudes and beliefs 
were broadly consistent within each cluster: there were no clusters exhibiting high responses for one factor such as interest but low responses for another factor such as utility. Students' attitudes and beliefs may be more closely related than previously assumed, which was also evident through the moderate to large intercorrelations between these factors. Students' intentions varied across the clusters and at year 10 even varied when accounting for the students' underlying attitudes and beliefs, highlighting that the clusters offered additional explanatory power and insight. Essentially, at year 10, students' intentions associated with holding a particular profile of attitudes and beliefs, over and above the independent effects of these attitudes and beliefs in themselves.

The majority of students remained in the same cluster over time. For those students who changed clusters, more students changed clusters reflecting an increase in attitudes than changed clusters reflecting a decrease (research aim 3), regardless of whether the three-cluster, four-cluster or five-cluster models were considered. Students in the cluster with the highest attitudes were most likely to remain within that cluster, regardless of whether the three-cluster, four-cluster or five-cluster models were considered. Conversely, students in clusters with lower attitudes were more likely to change clusters. Overall, there may be distinct groups of highly engaged students who are most likely to study physics further (cluster A in the various models), yet slightly more students transitioned into this cluster than transitioned out of it (regardless of whether the three-cluster, four-cluster or five-cluster models were considered) highlighting that change was still possible.

Essentially, the clusters highlighted naturally occurring proportions of students who might (or might not) study physics further, while concurrently providing plausible evidence that students' attitudes can change and even increase over time. Considered further, as detailed below, the findings variously support and extend prior research and raise wider implications.

\section{Predictive Modelling}

Students' intentions to study upper-secondary physics were most strongly predicted by their perceived advice, interest value of physics, utility value of physics, self-concept beliefs (their perceived expectancies/confidence in their abilities in physics), and home support specifically related to physics. This was not surprising, given that these factors followed from the expectancy-value and the planned behaviour models (Ajzen 1991; Eccles 2009; Wigfield and Cambria 2010). However, the expectancy-value model would assume that advice and home support have indirect associations with someone's intentions (via associating with subjective values or expectancies/confidence, which then associate with intentions), while the presented results confirmed a direct predictive association. Students' perceived advice to study physics had the highest predictive magnitude when considered at year 8 and at year 10 , although advice had no significant longitudinal predictive association when accounting for the other factors, suggesting that these relations may still be complex.

The influences of utility, interest and self-concept beliefs cohere with results from various prior studies, which have usually considered science as a whole rather than physics alone (DeWitt and Archer 2015; Mellors-Bourne et al. 2011; Sheldrake 2016; Tripney et al. 2010; Vidal Rodeiro 2007). Other research in England has highlighted the relevance of advice and encouragement, although at varying magnitudes (Archer et al. 2015a; DeWitt et al. 2016). Due to prior research covering different samples, analysed through different approaches, it remains difficult to definitively conclude whether any one factor is more important than any other. 
The results also highlighted potential differences between predictive associations at year 8 and year 10: self-concept beliefs had relatively higher predictive associations with intentions at year 10, while interest and utility had (slightly) relatively lower associations at year 10 . Inferring from prior research, influences may plausibly vary by age or the particular choice being considered. For example, in England, students' perceived utility of science has been strongly emphasised in relation to studying science at upper-secondary school (Vidal Rodeiro 2007), while students' interest in science has been strongly emphasised in relation to studying science at university (Mellors-Bourne et al. 2011). However, due to research applying varying methods, such as using predictive modelling of intentions (as undertaken here given that the students had not made their choices) or asking students to retrospectively list their reasons for choices, it remains difficult to understand any differences. Further longitudinal work specifically considering any changing influences over time may be beneficial.

Fundamentally, the results affirm that fostering students' attitudes and beliefs may be plausible approaches to help inspire more students to study non-compulsory physics. Specific advice and encouragement may be relevant, although future research may be necessary to clarify how different forms of advice may be interpreted and/or what approaches may be best. On a wider level, the results indicated that initial differences in intentions across students with different genders and ethnicities were essentially explained by these students holding different attitudes and beliefs: gender was not significantly predictive when considered in cross-sectional models together with students' attitudes and beliefs. However, when considered longitudinally, boys were predicted to have higher physics intentions at year 10 while accounting for their attitudes and beliefs at year 8 and their other background characteristics. Future research may need to explore more complex interactions of students' backgrounds, beliefs and their contexts, and/or apply more nuanced qualitative approaches, in order to clarify how and why different students have different trajectories towards or away from physics. Predictive models and cluster analysis help to provide an initial overview, for example, but interviewing students may be necessary to help understand why trajectories and changes actually occur.

\section{Cluster Analysis}

Latent-transition analysis via Markov models revealed naturally emergent clusters of students, where each cluster exhibited broadly consistent orientations towards physics (especially for those with generally higher attitudes and beliefs but with more variation for those with lower views), and where students' physics intentions varied across the clusters. Similar trends were observed across the three-cluster, four-cluster and five-cluster models.

Considering the three-cluster models for brevity, the clusters exhibited broadly coherent or consistent profiles of attitudes and beliefs, but with more variability and range of responses when attitudes were lower. Expressed briefly and simply, one cluster exhibited consistently positive responses across their interest value of physics, utility value of physics, advice to study physics and home support for physics, and also expressed positive intentions towards studying non-compulsory physics (cluster A: $20.5 \%$ of the sample at year 8 and $24.7 \%$ at year 10 ); another cluster mostly expressed slightly positive responses across these attitudes and beliefs but expressed ambivalence towards studying non-compulsory physics (cluster B: $52.0 \%$ at year 8 and $49.8 \%$ at year 10); and the final cluster expressed ambivalent to negative attitudes and intentions (cluster C: $27.5 \%$ at year 8 and $25.5 \%$ at year 10). The variability and range of responses was smaller for those with the highest attitudes and beliefs (cluster A). 
These naturally emergent cluster sizes differed from prior research that has, for example, involved researchers defining groups so that only $5 \%$ of a cross-sectional sample of students encompassing years 7 to 10 in England exhibited the highest levels of science extra-curricular engagement, perceived utility and other views, while $68 \%$ had medium levels and $27 \%$ had low levels (Archer et al. 2015a). Given that less research has applied cluster analysis in England, it may be informative to compare, in more detail, emergent clusters and artificial groups (formed through considering students with low, medium and high levels of interest in science, for example, but relying on researchers to specify the particular boundaries). Both approaches may offer insights in different contexts, or insights to answer different research questions.

The presented results broadly cohere with prior studies undertaken outside of England, which have similarly revealed clusters of students that exhibited broadly consistent attitudes within each cluster, such as these being generally high, moderate or low in magnitude (Andersen and Chen 2016; Andersen and Cross 2014; Conley 2012; Simpkins and DavisKean 2005). Nevertheless, one study revealed large clusters with proportionate beliefs (e.g. high responses for self-concept beliefs, expected attainment, interest and perceived utility), but smaller clusters with varying responses (e.g. moderate self-concept, low expectations, high interest and moderate utility), although via a geographically localised sample within the USA (Aschbacher et al. 2014). It remains possible that considering different populations and/or more extensive numbers of clusters might reveal more variation, although such clusters may also be smaller and harder to generalise from.

Considered broadly, there were no clusters that represented or suggested clear intervention points or approaches: a hypothetical cluster of students who expressed high interest but also had low perceived utility of physics, for example, might suggest an intervention towards fostering their perceived utility. For those students with the lowest responses (using the example of cluster $\mathrm{C}$ in the three-cluster models), responses ranged from disinterest in physics, and being disinclined to study physics further, to ambivalent views about the utility of physics but with slightly positive home support for physics. While some within-cluster variability can be observed in this way, the presented results broadly suggest that, within a practical context, concurrently fostering students' interest, utility and their other perceptions of physics may be beneficial.

Nevertheless, the presented results also revealed, when considering four-cluster and fivecluster models, a small cluster of students who strongly disagreed that they received any advice to study physics further (giving the lowest possible responses on the scale), while their other attitudes towards physics were generally ambivalent to negative. However, that cluster was small (encompassing only $3.5 \%$ of the sample at year 10), so it may be harder to generalise from. Nevertheless, further research may need to explore whether and/or why students might receive (or not receive) particular advice from teachers and others. Prior research has highlighted that some students have explained, within detailed interviews, that a lack of encouragement and support was a limiting factor to their science progression (Aschbacher et al. 2010). Future research may need to continue to consider whether and, if so, why some students might be explicitly discouraged to study physics or science, especially as the crosssectional predictive modelling highlighted that advice and encouragement associated with students' intentions towards studying non-compulsory physics.

The presented results also revealed differences in gender, ethnicity and prior attainment across the clusters, where (for example) boys were more represented within the cluster of students with the highest attitudes and intentions towards physics at year 8 and at year 10. It 
may be informative for research to continue to explore whether boys and girls who aspire towards science can be characterised by similar (or different) patterns of beliefs. Detailed qualitative studies may also be necessary to clarify whether and/or how boys and girls may apply similar or different approaches or strategies to engaging with science (e.g. Archer et al. 2017), perhaps even if they hold similarly high patterns of attitudes and beliefs.

Future research may also need to consider, in more detail, how students make concurrent choices across numerous subjects (which might involve mutually-exclusive choices between some subjects). Prior studies have highlighted that some differences may be more (or perhaps only) apparent when considered across subjects. For example, for secondary-school students in the USA, two clusters of students emerged with either consistently high or consistently moderate attitudes towards science, mathematics and English, while a third cluster emerged with low attitudes towards science and mathematics but higher attitudes towards English (Chow et al. 2012). Studies in England have often considered students' attitudes towards science in isolation (as undertaken here, considering physics alone), and it may be beneficial to concurrently consider students' attitudes towards other subjects. In the context of the presented results, it remains unknown whether those in the cluster with the highest attitudes towards physics also had high attitudes towards other subjects and/or whether some students favoured physics but disfavoured other subjects such as English or mathematics.

\section{Wider Implications}

The majority of students remained in the same cluster over time. Of those who moved clusters, more students changed clusters reflecting an increase in attitudes than changed clusters reflecting a decrease.

Considering the three-cluster models for brevity, only those in the cluster with the highest attitudes and beliefs (cluster A, $24.7 \%$ of the sample at year 10) positively intended to study physics further, while those in the other clusters were ambivalent or slightly negative in their intentions. While many students remained within this highest cluster over time (312 or $67.4 \%$ of the original cluster membership remained over time), more students moved into the cluster (246 students) than moved out of the cluster (151 students). Similar trends also occurred for the four-cluster and five-cluster models (but with varying numbers and percentages). This somewhat supports studies and commentaries that have critiqued or questioned 'pipeline' trajectories within science education, which assume increasing attrition away from science at each time or choice, while a core set of students persist (Blickenstaff 2005; Cannady et al. 2014). In contrast to 'pipeline' assumptions, the results presented here indicated that some students actually had higher attitudes towards science over time. While there may indeed be some students who consistently aspire towards science throughout their entire education, it may be beneficial for science education to facilitate other students to move into (or back into) studying science.

The presented results additionally highlighted that students in general did not necessarily hold negative attitudes towards physics. The largest clusters of students (cluster B in the threecluster models, cluster B in the four-cluster models and clusters B and C in the five-cluster models) expressed slightly positive physics attitudes (although cluster $\mathrm{C}$ in the five-cluster models tended towards ambivalence, responding around the mid-point for the various factors). These results broadly reflect prior studies in England, which have highlighted that while some attitudes towards science have declined over time, other attitudes have remained similar or even increased, and that any changes have not necessary entailed negative attitudes towards 
science (Bennett and Hogarth 2009; DeWitt et al. 2014). Similar changes have also been observed outside of England across different academic subjects (Archambault et al. 2010; Jacobs et al. 2002; Nagy et al. 2010; Simpson and Oliver 1990). In more detail, the results presented here highlighted that, on average across the entire sample, students' perceived utility of physics actually increased from year 8 to year 10, although students' intentions to study upper-secondary physics decreased. Similar, but not identical, changes have been observed in other studies. For example, in a longitudinal survey of secondary school students in Canada, the students' interest in science and technology declined over time but remained positive, while the students' perceived utility of science and the students' attraction to science and technology studies and careers increased over time (Potvin and Hasni 2014).

Overall, the presented results provide some reassurance that students' views regarding physics can increase during secondary education (and hence that educators could help support this), but future research may need to determine why different students' attitudes change in different ways. For example, the presented results cannot explain why particular transitions between clusters occurred, although the results highlighted some potential starting points for future explorations. Specifically, the presented results highlighted that, from year 8 to year 10, more girls than boys left the cluster with the most positive views regarding physics. The intersection between gender and physics has already been proposed to be problematic (e.g. physics is often perceived as 'male'), and it is possible that students may recognise this and/or increasingly encounter difficulties (Archer et al. 2017). For example, differences between perceptions of science or scientists (e.g. stereotyped as being white and/or male) and students' perceptions of their own identities may entail that science is not considered as a feasible study option for many students (Archer et al. 2013; Archer et al. 2015b). Concurrently, boys and girls may perceive their classrooms in different ways and/or be given different levels of support or advice (Lazarides and Watt 2015; Murphy and Whitelegg 2006; Wang 2012). Ultimately, it remains important to explore how different students' attitudes may be influenced in different ways, which is likely to require a range of qualitative and quantitative approaches.

\section{Limitations}

While the questionnaire covered a wide array of factors, other influences may be relevant to students' studying intentions. While the presented analysis covered a theoretically based set of factors (Bøe and Henriksen 2015; Eccles 2009), future research may still need to consider other potential influences in order to better understand students' intentions and choices, otherwise theoretical perspectives risk constraining research rather than acting as avenues to facilitate insight. Additionally, different results may follow from different samples of students, especially as the presented results followed from a generally higher-attaining sample of schools/ students (rather than from a purely random sample or a precisely nationallyrepresentative sample). More research with varying ages and populations of students remains beneficial.

On a wider level, and fundamentally, students' choices may differ from their intentions. Decision making remains complex and may not be perfectly represented through statistical abstractions: applying further, and multiple, research perspectives will likely continue to be insightful. The presented results offer potential starting 
points for quantitative research to further consider how students' attitudes and intentions change over time, and qualitative research to further consider why changes might occur and to clarify students' subjective experiences. For example, revealing and considering clusters of students with different profiles of attitudes and beliefs may link with considering students' science identities, which has usually been undertaken through qualitative approaches (e.g. Aschbacher et al. 2010; Holmegaard et al. 2014; Wong 2016). Science identity may encompass self-recognition of being a science person, for example, together with recognition from others (Carlone and Johnson 2007). Future research could consider whether students perceive that an idealised 'science identity' involves someone having consistently high confidence, high interest, and other attitudes towards science, for example, and/or consider whether other combinations of attitudes and beliefs are compatible (or not) with self-recognition of a science identity (and/or being recognised by others and given encouragement and support). Detailed qualitative approaches may be necessary to explore how the close coherence (or contrasts) between students' various attitudes and beliefs, within the context of wider socio-cultural norms and other influences, may form aspects of their identities and/or influence their studying intentions.

\section{Conclusions}

Students' intentions to study (non-compulsory) upper-secondary physics were predicted by their perceived advice, perceived utility of physics, interest in physics, self-concept beliefs (students' subjective beliefs of their current abilities and performance) and home support specifically orientated to physics. These results affirm that fostering these attitudes and beliefs may be plausible approaches to help increase the number of students who study noncompulsory physics.

Clusters of students were revealed, where students' attitudes and beliefs towards physics were broadly consistent in magnitude within each cluster (especially for those with generally higher attitudes and beliefs but with more variation for those with lower views). There were no clusters where students clearly exhibited high attitudes or beliefs in one area (such as interest) but low attitudes in another area (such as utility), which might suggest a single intervention point. Within a practical context, it may be beneficial to concurrently foster students' interest, utility and their other perceptions of physics, while also providing advice and encouragement.

The majority of students remained in the same cluster over time; nevertheless, for those students who changed clusters, more students changed clusters reflecting an increase in attitudes than changed clusters reflecting a decrease. Students in the cluster with the highest attitudes and intentions towards physics were most likely to remain within that cluster; conversely, students in clusters with lower attitudes were more likely to change clusters.

Overall, these results provide reassurance that students' attitudes and beliefs towards physics can positively change over time during secondary education, although not necessarily for all students. It remains important to explore how different students' attitudes and aspirations may be influenced in different ways: specifically, the results indicated that girls were more likely to move out of the cluster with the highest attitudes and intentions towards physics, but further quantitative and qualitative research will be necessary in order to understand why. 
Acknowledgements This work was supported by the Economic and Social Research Council (ESRC) [RES179-25-0013]. Please contact the lead author regarding access to the underlying research materials if required.

Compliance with Ethical Standards Before data collection commenced, the study was reviewed and approved by the ethics committee of the host institution. The study was undertaken under established guidelines for ethical practice (BERA 2011). Informed consent to participate was facilitated via the provision of information material (which was reiterated on the questionnaires), and participation was voluntary. Students were free to withdraw from the study at any time, and/or to not respond to any (or all) items on the questionnaire.

Conflict of Interest The authors declare that they have no conflict of interest.

Open Access This article is distributed under the terms of the Creative Commons Attribution 4.0 International License (http://creativecommons.org/licenses/by/4.0/), which permits unrestricted use, distribution, and reproduction in any medium, provided you give appropriate credit to the original author(s) and the source, provide a link to the Creative Commons license, and indicate if changes were made.

\section{References}

ACOLA [Australian Council of Learned Academies]. (2013). STEM: Country comparisons: International comparisons of science, technology, engineering and mathematics (STEM) education. Melbourne: Australian Council of Learned Academies.

Ajzen, I. (1991). The theory of planned behavior. Organizational Behavior and Human Decision Processes, 50(2), 179-211. https://doi.org/10.1016/0749-5978(91)90020-T.

Andersen, L., \& Chen, J. (2016). Do high-ability students disidentify with science? A descriptive study of U.S. ninth graders in 2009. Science Education, 100(1), 57-77. https://doi.org/10.1002/sce.21197.

Andersen, L., \& Cross, T. (2014). Are students with high ability in math more motivated in math and science than other students? Roeper Review, 36(4), 221-234. https://doi.org/10.1080/02783193.2014.945221.

Archambault, I., Eccles, J., \& Vida, M. (2010). Ability self-concepts and subjective value in literacy: Joint trajectories from grades 1 through 12. Journal of Educational Psychology, 102(4), 804-816. https://oi. org/10.1037/a0021075.

Archer, L., \& Francis, B. (2006). Challenging classes? Exploring the role of social class within the identities and achievement of British Chinese pupils. Sociology, 40(1), 29-49. https://doi.org/10.1177 $/ 0038038506058434$.

Archer, L., DeWitt, J., Osborne, J., Dillon, J., Willis, B., \& Wong, B. (2013). 'Not girly, not sexy, not glamorous': Primary school girls' and parents' constructions of science aspirations. Pedagogy, Culture \& Society, 21(1), 171-194. https://doi.org/10.1080/14681366.2012.748676.

Archer, L., DeWitt, J., \& Wong, B. (2014). Spheres of influence: What shapes young people's aspirations at age $12 / 13$ and what are the implications for education policy? Journal of Education Policy, 29(1), 58-85. https://doi.org/10.1080/02680939.2013.790079.

Archer, L., Dawson, E., DeWitt, J., Seakins, A., \& Wong, B. (2015a). "Science capital”: A conceptual, methodological, and empirical argument for extending Bourdieusian notions of capital beyond the arts. Journal of Research in Science Teaching, 52(7), 922-948. https://doi.org/10.1002/tea.21227.

Archer, L., DeWitt, J., \& Osborne, J. (2015b). Is science for us? Black students' and parents' views of science and science careers. Science Education, 99(2), 199-237. https://doi.org/10.1002/sce.21146.

Archer, L., Moote, J., Francis, B., DeWitt, J., \& Yeomans, L. (2017). The "exceptional” physics girl: A sociological analysis of multimethod data from young women aged 10-16 to explore gendered patterns of post-16 participation. American Educational Research Journal, 54(1), 88-126. https://doi.org/10.3102 /0002831216678379.

Aschbacher, P., Li, E., \& Roth, E. (2010). Is science me? High school students' identities, participation and aspirations in science, engineering, and medicine. Journal of Research in Science Teaching, 47(5), 564-582. https://doi.org/10.1002/tea.20353.

Aschbacher, P., Ing, M., \& Tsai, S. (2014). Is science me? Exploring middle school students' STE-M career aspirations. Journal of Science Education and Technology, 23(6), 735-743. https://doi.org/10.1007/s10956014-9504-x.

Bandura, A. (1977). Self-efficacy: Toward a unifying theory of behavioral change. Psychological Review, 84(2), 191-215. https://doi.org/10.1037/0033-295X.84.2.191.

Bates, P., Pollard, E., Usher, T., \& Oakley, J. (2009). Who is heading for HE? Young People's perceptions of, and decisions about, higher education. London: Department for Business, Innovation and Skills. 
Bennett, J., \& Hogarth, S. (2009). Would you want to talk to a scientist at a party? High school students' attitudes to school science and to science. International Journal of Science Education, 31(14), 1975-1998. https://oi. org/10.1080/09500690802425581.

Bennett, J., Lubben, F., \& Hampden-Thompson, G. (2013). Schools that make a difference to post-compulsory uptake of physical science subjects: Some comparative case studies in England. International Journal of Science Education, 35(4), 663-689. https://doi.org/10.1080/09500693.2011.641131.

BERA [British Educational Research Association]. (2011). Ethical guidelines for educational research. Retrieved July 1, 2017, from British Educational Research Association: https://www.bera.ac.uk/wpcontent/uploads/2014/02/BERA-Ethical-Guidelines-2011.pdf.

Blickenstaff, J. C. (2005). Women and science careers: Leaky pipeline or gender filter? Gender and Education, 17(4), 369-386. https://doi.org/10.1080/09540250500145072.

Bøe, M. V. (2012). Science choices in Norwegian upper secondary school: What matters? Science Education, 96(1), 1-20. https://doi.org/10.1002/sce.20461.

Bøe, M. V., \& Henriksen, E. K. (2013). Love it or leave it: Norwegian students' motivations and expectations for postcompulsory physics. Science Education, 97(4), 550-573. https://doi.org/10.1002/sce.21068.

Bøe, M. V., \& Henriksen, E. K. (2015). Expectancy-value perspectives on choice of science and technology education in late-modern societies. In E. K. Henriksen, J. Dillon, \& J. Ryder (Eds.), Understanding student participation and choice in science and technology education (pp. 17-29). Dordrecht: Springer. https://oi. org/10.1007/978-94-007-7793-4_2.

Bong, M., \& Clark, R. (1999). Comparison between self-concept and self-efficacy in academic motivation research. Educational Psychologist, 34(3), 139-153. https://doi.org/10.1207/s15326985ep3403_1.

Bong, M., \& Skaalvik, E. (2003). Academic self-concept and self-efficacy: How different are they really? Educational Psychology Review, 15(1), 1-40. https://doi.org/10.1023/A:1021302408382.

Cannady, M., Greenwald, E., \& Harris, K. (2014). Problematizing the STEM pipeline metaphor: Is the STEM pipeline metaphor serving our students and the STEM workforce? Science Education, 98(3), 443-460. https://doi.org/10.1002/sce.21108.

Carlone, H., \& Johnson, A. (2007). Understanding the science experiences of successful women of color: Science identity as an analytic lens. Journal of Research in Science Teaching, 44(8), 1187-1218. https://oi. org/10.1002/tea.20237.

Chow, A., Eccles, J., \& Salmela-Aro, K. (2012). Task value profiles across subjects and aspirations to physical and IT-related sciences in the United States and Finland. Developmental Psychology, 48(6), 1612-1628. https://doi.org/10.1037/a0030194.

Collins, L., \& Lanza, S. (2010). Latent class and latent transition analysis: With applications in the social, behavioral, and health sciences. Hoboken: Wiley.

Conley, A. (2012). Patterns of motivation beliefs: Combining achievement goal and expectancy-value perspectives. Journal of Educational Psychology, 104(1), 32-47. https://doi.org/10.1037/a0026042.

Department for Education. (2017). Find and compare schools in England. Retrieved October 1, 2017, from Department for Education: https://www.gov.uk/school-performance-tables

DeWitt, J., \& Archer, L. (2015). Who aspires to a science career? A comparison of survey responses from primary and secondary school students. International Journal of Science Education, 37(13), 2170-2192. https://doi.org/10.1080/09500693.2015.1071899.

DeWitt, J., Archer, L., Osborne, J., Dillon, J., Willis, B., \& Wong, B. (2011). High aspirations but low progression: The science aspirations-careers paradox amongst minority ethnic students. International Journal of Science and Mathematics Education, 9(2), 243-271. https://doi.org/10.1007/s10763-010-9245-0.

DeWitt, J., Archer, L., \& Osborne, J. (2014). Science-related aspirations across the primary-secondary divide: Evidence from two surveys in England. International Journal of Science Education, 36(10), 1609-1629. https://doi.org/10.1080/09500693.2013.871659.

DeWitt, J., Archer, L., \& Mau, A. (2016). Dimensions of science capital: Exploring its potential for understanding students' science participation. International Journal of Science Education, 38(16), 2431-2449. https://doi.org/10.1080/09500693.2016.1248520.

EACEA [Education, Audiovisual, and Culture Executive Agency]. (2011). Science education in Europe: National policies, practices and research. Brussels: European Commission. https://doi.org/10.2797/7170.

Eccles, J. (2009). Who am I and what am I going to do with my life? Personal and collective identities as motivators of action. Educational Psychologist, 44(2), 78-89. https://doi.org/10.1080/00461520902832368.

Eccles, J., \& Wang, M.-T. (2016). What motivates females and males to pursue careers in mathematics and science? International Journal of Behavioral Development, 40(2), 100-106. https://doi.org/10.1177 /0165025415616201.

Eccles, J., Adler, T., Futterman, R., Goff, S., Kaczala, C., Meece, J., \& Midgley, C. (1983). Expectancies, values and academic behaviors. In J. Spence (Ed.), Achievement and achievement motives (pp. 75-146). San Francisco: W. H. Freeman. 
Everitt, B., Landau, S., Leese, M., \& Stahl, D. (2011). Cluster analysis (5th ed.). Chichester: Wiley.

Gill, T., \& Bell, J. (2013). What factors determine the uptake of A-level physics? International Journal of Science Education, 35(5), 753-772. https://doi.org/10.1080/09500693.2011.577843.

Guo, J., Nagengast, B., Marsh, H., Kelava, A., Gaspard, H., Brandt, H., et al. (2016). Probing the unique contributions of self-concept, task values, and their interactions using multiple value facets and multiple academic outcomes. AERA Open, 2(1), 1-20. https://doi.org/10.1177/2332858415626884.

Holmegaard, H. T., Ulriksen, L., \& Madsen, L. M. (2014). The process of choosing what to study: A longitudinal study of upper secondary students' identity work when choosing higher education. Scandinavian Journal of Educational Research, 58(1), 21-40. https://doi.org/10.1080/00313831.2012.696212.

Homer, M., Ryder, J., \& Banner, I. (2014). Measuring determinants of post-compulsory participation in science: A comparative study using national data. British Educational Research Journal, 40(4), 610-636. https:/doi. org/10.1002/berj.3106.

IBM. (2014). IBM SPSS Missing Values 22. IBM. Retrieved July 1, 2017, from ftp://public.dhe.ibm. com/software/analytics/spss/documentation/statistics/22.0/en/client/Manuals/IBM_SPSS_Missing_Values. pdf.

Institute of Physics. (2014). Raising aspirations in physics: A review of research into barriers to STEM participation for students from disadvantaged backgrounds. London: Institute of Physics.

Jacobs, J., Lanza, S., Osgood, D. W., Eccles, J., \& Wigfield, A. (2002). Changes in Children's self-competence and values: Gender and domain differences across grades one through twelve. Child Development, 73(2), 509-527. https://doi.org/10.1111/1467-8624.00421.

Jenkins, E., \& Nelson, N. (2005). Important but not for me: Students' attitudes towards secondary school science in England. Research in Science and Technological Education, 23(1), 41-57. https://doi.org/10.1080 $/ 02635140500068435$.

Jensen, F., \& Henriksen, E. K. (2015). Short stories of educational choice: In the words of science and technology students. In E. K. Henriksen, J. Dillon, \& J. Ryder (Eds.), Understanding student participation and choice in science and technology education (pp. 135-151). Dordrecht: Springer. https://doi.org/10.1007/978-94-0077793-4_9.

Lazarides, R., \& Watt, H. (2015). Girls' and boys' perceived mathematics teacher beliefs, classroom learning environments and mathematical career intentions. Contemporary Educational Psychology, 41, 51-61. https://doi.org/10.1016/j.cedpsych.2014.11.005.

Mellors-Bourne, R., Connor, H., \& Jackson, C. (2011). STEM graduates in non-STEM jobs. London: Department for Business, Innovation and Skills.

Murphy, P., \& Whitelegg, E. (2006). Institute of Physics report: Girls in the physics classroom: A review of the research on the participation of girls in physics. London: Institute of Physics.

Nagy, G., Watt, H., Eccles, J., Trautwein, U., Lüdtke, O., \& Baumert, J. (2010). The development of students' mathematics self-concept in relation to gender: Different countries, different trajectories? Journal of Research on Adolescence, 20(2), 482-506. https://doi.org/10.1111/j.1532-7795.2010.00644.x.

Peugh, J., \& Enders, C. (2004). Missing data in educational research: A review of reporting practices and suggestions for improvement. Review of Educational Research, 74(4), 525-556. https://doi.org/10.3102 /00346543074004525.

Potvin, P., \& Hasni, A. (2014). Analysis of the decline in interest towards school science and technology from grades 5 through 11. Journal of Science Education and Technology, 23(6), 784-802. https://doi.org/10.1007 /s10956-014-9512-x.

Regan, E., \& DeWitt, J. (2015). Attitudes, interest and factors influencing STEM enrolment behaviour: An overview of relevant literature. In E. K. Henriksen, J. Dillon, \& J. Ryder (Eds.), Understanding student participation and choice in science and technology education (pp. 63-88). Dordrecht: Springer. https://oi. org/10.1007/978-94-007-7793-4_5.

Royal Society. (2008). Science and mathematics education, 14-19: A 'state of the nation' report on the participation and attainment of 14-19 year olds in science and mathematics in the UK, 1996-2007. London: The Royal Society.

Royal Society. (2014). Vision for science and mathematics education. London: The Royal Society.

Sheldrake, R. (2016). Students' intentions towards studying science at upper-secondary school: The differential effects of under-confidence and over-confidence. International Journal of Science Education, 38(8), 12561277. https://doi.org/10.1080/09500693.2016.1186854.

Simpkins, S., \& Davis-Kean, P. (2005). The intersection between self-concepts and values: Links between beliefs and choices in high school. New Directions for Child and Adolescent Development, 2005(110), 31-47. https://doi.org/10.1002/cd.148.

Simpson, R., \& Oliver, J. S. (1990). A summary of major influences on attitude toward and achievement in science among adolescent students. Science Education, 74(1), 1-18. https://doi.org/10.1002 /sce.3730740102. 
Snijders, T., \& Bosker, R. (2012). Multilevel analysis: An introduction to basic and advanced multilevel modeling (2nd ed.). London: SAGE Publications.

Thomas, J., \& Strunk, K. (2017). Expectancy-value and Children's science achievement: Parents matter. Journal of Research in Science Teaching, 54, 1-20. https://doi.org/10.1002/tea.21382.

Tripney, J., Newman, M., Bangpan, M., Niza, C., MacKintosh, M., \& Sinclair, J. (2010). Factors influencing young people (aged 14-19) in education about STEM subject choices: A systematic review of the UK literature. London: Wellcome Trust.

Vermunt, J., \& Magidson, J. (2016). Technical guide for latent GOLD 5.1: Basic, advanced, and syntax. Belmont: Statistical Innovations Retrieved July 1, 2017, from http:/www.statisticalinnovations.com/wpcontent/uploads/LGtecnical.pdf.

Vidal Rodeiro, C. (2007). A level subject choice in England: Patterns of uptake and factors affecting subject preferences. Cambridge: Cambridge Assessment.

Wang, M.-T. (2012). Educational and career interests in math: A longitudinal examination of the links between classroom environment, motivational beliefs, and interests. Developmental Psychology, 48(6), 1643-1657. https://doi.org/10.1037/a0027247.

Wang, M.-T., \& Degol, J. (2013). Motivational pathways to STEM career choices: Using expectancy-value perspective to understand individual and gender differences in STEM fields. Developmental Review, 33(4), 304-340. https://doi.org/10.1016/j.dr.2013.08.001.

Wang, M.-T., Eccles, J., \& Kenny, S. (2013). Not lack of ability but more choice: Individual and gender differences in choice of careers in science, technology, engineering, and mathematics. Psychological Science, 24(5), 770-775. https://doi.org/10.1177/0956797612458937.

Wigfield, A., \& Cambria, J. (2010). Students' achievement values, goal orientations, and interest: Definitions, development, and relations to achievement outcomes. Developmental Review, 30(1), 1-35. https://oi. org/10.1016/j.dr.2009.12.001.

Wigfield, A., \& Eccles, J. (2000). Expectancy-value theory of achievement motivation. Contemporary Educational Psychology, 25(1), 68-81. https://doi.org/10.1006/ceps.1999.1015.

Wong, B. (2012). Identifying with science: A case study of two 13-year-old 'high achieving working class' British Asian girls. International Journal of Science Education, 34(1), 43-65. https://doi.org/10.1080 /09500693.2010.551671.

Wong, B. (2016). Minority ethnic students and science participation: A qualitative mapping of achievement, aspiration, interest and capital. Research in Science Education, 46(1), 113-127. https://doi.org/10.1007 /s11165-015-9466-x. 